\title{
FUZZY FINITE ELEMENT ANALYSIS FOR STATIC RESPONSES OF PLANE STRUCTURES
}

\author{
Tuan Hung NGUYEN ${ }^{1,{ }^{*}, \text { Huynh Xuan LE }}{ }^{2}$, Ha Phuong DO ${ }^{1}$ \\ ${ }^{1}$ Faculty of Civil Engineering, Thuyloi University, 175 Tay Son, Dong Da, Hanoi, Vietnam. \\ ${ }^{2}$ National University of Civil Engineering, 55 Giai Phong, Hai Ba Trung, Hanoi, Vietnam. \\ * corresponding author: hungtuan@tlu.edu.vn
}

\begin{abstract}
In this paper, a fuzzy finite element algorithm is investigated to determine static responses of plane structures. This algorithm concerns finite element method, fuzzy sets theory, and response surface method. Firstly, the notion of a standardized triangular fuzzy number is developed and utilized to replace original fuzzy numbers in the surrogate models. Then, the error estimations between the training and the test sets are performed to select the suitable response surface model amongst the regression models. Lastly, a good performance combination of complete and non-complete quadratic polynomial regression models is proposed to define the responses of structures. The merits of the proposed algorithm are illustrated via numerical exambles.
\end{abstract}

\author{
Keywords: \\ Fuzzy sets theory; \\ Fuzzy finite element; \\ Response surface method; \\ Possibility-probability \\ transformations; \\ Generalized similarity measure.
}

\section{Introduction}

Fuzzy finite element method (FFEM) is the combination of finite element method (FEM) and fuzzy sets theory [1] to define the responses of structures in the case that the input quantities such as loads, material and geometry properties, stiffness of supports, contain incomplete information, which is described in the form of fuzzy numbers. In recent years, a large number of FFEM have been proposed, from static analysis to extension in dynamic analysis of structures. Fundamental strategies of FFEM can be categorized into main groups as follows: the interval arithmetic approach for static analysis of structures [2-8], the optimization strategy for static and dynamic analysis of structures [9-20], the combination of interval arithmetic and optimization strategy for dynamic analysis of structures [21-23], applying perturbation method [24] in the stochastic finite element methods [25] for fuzzy analysis of structures [26-28]. In which, applying the response surface method (RSM) [29] is presented by $[16,17]$ based on optimization techniques is extremely valuable in the fuzzy analysis of structures. The advantage of this method is time reduction in each iterative evaluation by replacing the implicit goal functions with the pre-determined approximate response functions. The publications $[16,17]$ applied RSM to define fuzzy displacement for static analysis and fuzzy natural frequency [16], fuzzy envelope frequency functions for dynamic analysis [17].

In those works, all original fuzzy variables are presented in the surrogate model. This can lead to errors due to round-off in calculating regression coefficients when the fuzzy variables have very different domains. Besides that, co-linearity can occur as the fuzzy variables are correlated to each other. To overcome these drawbacks, the study [19] presented a notion for the standardized fuzzy variable of symmetric triangular fuzzy numbers and an algorithm for calculating fuzzy displacements of free vibration analysis. The publication [30] used this notion for the stability problem of steel frame with fixity factor modeled as a symmetric triangular fuzzy number. Based on the response surface method, this paper proposes a fuzzy finite element algorithm to determine both fuzzy displacements and fuzzy internal forces for static analysis of plane structures when the input quantities are general triangular fuzzy numbers. The first novelty of the present study is to define the standardized fuzzy variables of the general triangular fuzzy numbers. As a result, the very different domains of the original fuzzy variables can be transformed into the approximate equivalent domains of the standardized fuzzy variables. So the errors due to round-off in calculating regression coefficients would be eliminated and 
the response surface models are directly utilized to calculate fuzzy responses of structures. Then, the least-squares error criterion between the training and the test sets is used to select the suitable response surface model amongst the regression models. The last novelty of this paper is to propose the reasonable combination of complete and non-complete quadratic regression models for calculating fuzzy internal forces. Consequently, the narrowest width of each fuzzy internal force based on two of these models is gained, and the results of fuzzy internal forces are very close to the "exact results". The proposed algorithm is verified via several numerical examples.

\section{Fuzzy analysis algorithm}

\subsection{The standardized fuzzy variables}

The standardized fuzzy variables are utilized to calculate regression coefficients in the surrogate model. The standardized fuzzy variable is an equivalent notion as the notion of a normal variable in the probability-statistical theory. To define the standardized fuzzy variable, the insufficient reason principle [31-33] for the transformation from a fuzzy measure to a probability measure is applied. For the general triangular fuzzy number $\widetilde{x_{l}}=(a, l, r)_{L R}$ (Fig. 1), the probability density function of an equivalent random variable is derived as follows

$p\left(x_{i}\right)=\left\{\begin{array}{l}-\frac{1}{(l+r)} \ln \left(\frac{a-x_{i}}{l}\right) ; x_{i} \in[a-l, a) \\ -\frac{1}{(l+r)} \ln \left(\frac{x_{i}-a}{r}\right) ; x_{i} \in(a, a+r]\end{array}\right.$,

where:

$a$ - the belief value (at membership level $\mu=1$ ) of general triangular fuzzy number,

$I$ - the left spread of general fuzzy triangular number,

$r$ - the right spread of general fuzzy triangular number.

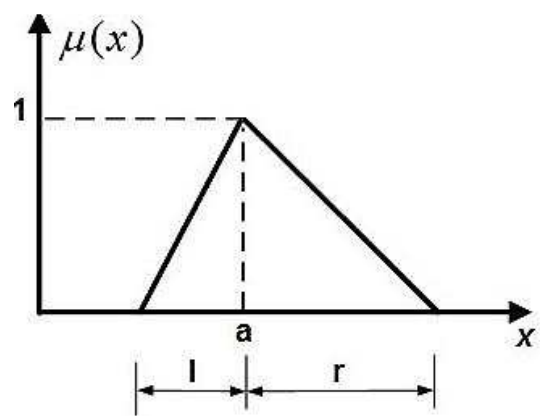

Fig. 1: The general triangular fuzzy number.

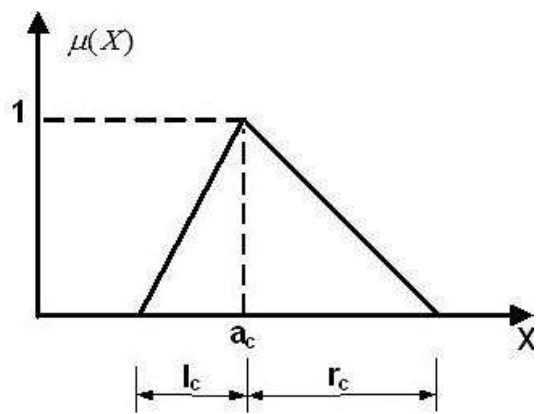

Fig. 2: The standardized fuzzy number.

The mean value $\mu_{1}$ and the standard deviation value $\sigma^{2}$ of the equivalent random variable are calculated as follows

$\mu_{i}=\int_{a-l}^{a+r} x_{i} p\left(x_{i}\right) d x_{i}$

$\sigma_{i}^{2}=\int_{a-i}^{a+r} x_{i}^{2} p\left(x_{i}\right) d x_{i}-\mu_{i}^{2}$.

Replacing (1) into (2), (3) and some manipulations are utilized, the below formulae are given

$\mu_{i}=a-\frac{(l-r)}{4}$,

$\sigma_{i}^{2}=\frac{7\left(l^{2}+r^{2}\right)+2 l r}{144}$.

The standardized fuzzy variable of general triangular one is defined as follows

$X_{i}=\frac{x_{i}-\mu_{i}}{s_{i}}=\frac{x_{i}-a+\frac{(l-r)}{4}}{\sqrt{7\left(l^{2}+r^{2}\right)+2 l r / 12}}$. 
The formula (6) transformed from the original fuzzy variable $\widetilde{x_{l}}=(a, l, r)_{L R}$ into the standardized fuzzy variable $\widetilde{X}_{l}=\left(a_{c}, l_{c}, r_{c}\right)_{L R}$, of which the central value $a_{c}$, the left spread $l_{c}$, and the right spread $r_{c}$ are determined as follows

$a_{c}=\frac{(l-r)}{4}$,

$l_{c}=\frac{(l-r)}{4}+\frac{3(r+3 l)}{\sqrt{7\left(l^{2}+r^{2}\right)+2 l r}}$,

$r_{c}=\frac{3(l+3 r)}{\sqrt{7\left(l^{2}+r^{2}\right)+2 l r}}-\frac{(l-r)}{4}$.

From the formulae (7), (8), and (9), one realizes that in the case of symmetric triangular fuzzy numbers, we have $a_{c}=0$ and $l_{c}=r_{c}=3$. In other words, the operation of transformation in [19] is a special case of the formulae (7), (8), and (9). With this transformation, the design variables in the surrogate models are the standardized fuzzy ones determined by the formulae (6), (7), (8), and (9). The universe of the original fuzzy variables is replaced by that of the standardized fuzzy variables, which has a similar meaning as the universe of normal random variables in the probability theory. Nevertheless, calculating fuzzy responses of structures is performed in the universe of these fuzzy variables, so the errors due to transforming from fuzzy variables into random variables such as the method [26] would be eliminated. Moreover, using the standardized fuzzy variables also excluded the errors due to round-off in calculating regression coefficients in the surrogate models [19].

\subsection{Design of experiments}

The design of experiments is the sampling plan in the design variable space. It plays a vital role in determining the regression coefficients of surrogate models. The important problem of it is how we evaluate the goodness of such designs with a limited number of samples. In the present paper, the Box-Behnken design [29] which has good results in actual problems is used when the number of design variables is exceeded two. When the number of design variables is two, the central composite design [29] is selected to design experiments.

\subsection{Surrogate models}

In the statistical theory, surrogate models are often used including the polynomial regression model, Kringing model, radial basis function [34]. Two- first models are parametric models, based on the assumed functional form of the response in terms of the design variables; the last model using different types of local models in different regions of the data to build up an overall model is nonparametric. Amongst these models, the polynomial regression model is often used to build a response surface function due to its calculation simplicity. In this paper, both the complete and non-complete quadratic polynomial regression model is used as regression models for the fuzzy displacements of structures, in which all fuzzy variables $X_{i}$ are standardized and assumed to be uncorrelated

The complete quadratic polynomial regression model (the CQP model)

$y(X)=a_{o}+\sum_{i=1}^{n} a_{i} X_{i}+\sum_{i=1, i<j}^{n-1} a_{i j} X_{i} X_{j}+\sum_{i=1}^{n} a_{i i} X_{i}^{2}$.

The non-complete quadratic polynomial regression model (the N-CQP model)

$y(X)=a_{o}+\sum_{i=1}^{n} a_{i} X_{i}+\sum_{i=1}^{n} a_{i i} X_{i}^{2}$.

According to the extension principle [1], the belief value of the fuzzy response of structures is received from the combination of belief values of input data. Hence, surrogate models in the formulae (10) and (11) need to respond to this constrained condition, such as

$y\left(\mathrm{X}=\mathrm{a}_{\mathrm{c}}\right)=\hat{y}(\mathrm{x}=\mathrm{a})$,

where is displacements at the membership level $\mu=1$ of the input data, which is determined by classical FEM. 
The regression coefficients of the formulae (10) and (11) are determined by the least-squares method, with the constrained condition of formula (12).

\subsection{Error estimation and selecting a reasonable design}

Error estimation assesses the quality of the response surface and is used to select a suitable design. The split sample, cross-validation, and bootstrapping methods are always to use, in which two-first methods are easy to apply. Due to separating between training and test sets as well as limiting the amount of data built into the surrogate model, the error estimation of the split sample method can get a high variance. On the contrary, the cross-validation method builds the surrogate models from most of the available data. For this reason, this method provides a nearly unbiased estimation of the generalization error and the corresponding variance is reduced when compared to the split sample method [34]. However, the cross-validation method requires many calculations of surrogate models. To overcome this limitation, one can use automatic programming to select the combinations of experiments from pre-determining experiments to construct the regression model. In the present study, the leave-one-out cross-validation is applied, where each response point is tested once and trained $k-1$ times since the center point has been used to equal the restrain condition of formula (12). The error estimation of ${ }^{j^{\text {th }}}$ design (using $\boldsymbol{X}^{(j)}$ as the test set) is determined by the formula

$G S E_{j}=\left(y_{j}-\hat{y}_{j}^{(-j)}\right)^{2}$,

where:

GSE $_{j}$ - the square error estimation of $j^{\text {th }}$ design,

$y_{j}$ - output value at $\boldsymbol{X}^{(j)}$, determined by classical FEM,

$y_{j}^{(-)}$- estimated value at $\boldsymbol{X}^{(j)}$ of $j^{\text {th }}$ design.

The design has the least-squares error estimation is selected to calculate fuzzy responses of structures.

\subsection{Determination for fuzzy responses of structures}

To determine fuzzy responses of structures, the nonlinear optimization problems need to perform at the pre-defined $\alpha$ - levels of the input data. Global optimization techniques such as genetic algorithm (GA), particle swarm optimization (PSO), differential evolution (DE) are considered to be suitable approaches for solving fuzzy problems. For the proposed algorithm, GA [35] using the built-in functions in MATLAB is applied to compute it. Subsections 2.5.1 and 2.5.2 present the innovations focussing on enhancing the degree of accuracy for both fuzzy displacements and fuzzy internal forces of structures.

\subsubsection{Fuzzy displacements of structures}

In the present paper, fuzzy displacements are determined directly by solving the nonlinear optimization problems of the response surface functions. Therefore, the complete quadratic polynomial regression function is more general and accurate than the non-complete one. As a consequence, the complete quadratic polynomial function that has the least-squares error estimation is selected to calculate fuzzy displacements of structures.

\subsubsection{Fuzzy internal forces of structures}

Fuzzy internal forces are indirectly determined by the formula: $R_{e}=K_{e} u_{e}-F_{e}$. As a result, fuzzy internal forces are less accurate than fuzzy displacements. To enhance the degree accuracy of fuzzy internal forces, the intersections between fuzzy internal forces calculated based on complete and noncomplete quadratic regression models are utilized, lower and upper bounds of fuzzy internal forces at the $\alpha$-levels are given as follows

$$
\begin{aligned}
& S_{\alpha \min }=\max \left(S_{\alpha 1, \min } ; S_{\alpha 2, \min }\right), \\
& S_{\alpha \max }=\min \left(S_{\alpha 1, \max } ; S_{\alpha 2, \max }\right),
\end{aligned}
$$


where:

- $S_{\alpha \min }, S_{\alpha \max }$ lower and upper bounds of fuzzy internal forces at the $\alpha$-levels of the proposed algorithm, - $S_{\alpha 1 \min }, S_{\alpha 1 \max }$ lower and upper bounds of fuzzy internal forces at the $\alpha$-levels using complete quadratic polynomial models for fuzzy displacements,

- $S_{\alpha 2 \min }, S_{\alpha 2 \max }$ lower and upper bounds of fuzzy internal forces at the a-levels using noncomplete quadratic polynomial models for fuzzy displacements.

The formulae (14) and (15) create the narrowest margins of fuzzy internal forces from the two surrogate models (complete and non-complete quadratic polynomial models). For the mathematics meaning, the formulae (14) and (15) express the operation of intersection on two fuzzy sets $A$ and $B$. According to [1], between fuzzy sets of $A, B$, and $A \cap B$, generic elements $x_{i}$ of fuzzy set $A \cap B$ have the least membership value. As a consequence, the widths of fuzzy internal forces at the $\alpha$-levels could be decreased by using the formulae (14) and (15), in other words, the results of fuzzy internal forces get more accurately. This problem is demonstrated via several numerical examples in the subsequent section.

Lastly, let us consider the special context when the fuzzy global stiffness matrix $\widetilde{\mathbf{K}}$ is represented as follows

$\widetilde{\mathbf{K}}=\tilde{E} \cdot \overline{\mathbf{K}}_{\mathbf{u}}$

where:

$\tilde{E}$ - the fuzzy elastic modulus of material,

$\overline{\mathbf{K}}_{\mathbf{u}}$ - the matrix of which all elements are deterministic values.

In this context, fuzzy internal forces are independent of the fuzzy elastic modulus of the material. Hence, fuzzy internal forces only depend on fuzzy loads and are triangular fuzzy numbers. The below formulae are given to yield a slightly better marginal of fuzzy internal forces

$S_{\text {min }}^{0}=S_{d e r}\left(x_{1 m i n}^{0}, x_{2 m i n}^{0}, \ldots, x_{\text {imin }}^{0}, \ldots, x_{n \min }^{0}\right)$,

$S_{\max }^{0}=S_{d e r}\left(x_{1 \max }^{0}, x_{2 \max }^{0}, \ldots, x_{i \max }^{0}, \ldots, x_{\text {max }}^{0}\right)$,

where:

$S_{\min }^{0}, S_{\max }^{0}$ - lower and upper bounds of fuzzy internal forces at the membership level $\alpha=0$,

$x_{\text {imin }}^{0}, x_{\text {imax }}^{0}$ - solutions for fuzzy input variable $\widetilde{x_{l}}$ are to reach the minimization and maximization values $S_{\alpha \min }, S_{\alpha \max }$ of objective functions at the membership level $\alpha=0$ according to the formulae (14) and (15), respectively,

$S_{\text {der }}()$ - values of internal forces are calculated by FEM.

\section{Numerical examples and discussions}

\subsection{Example 1}

Consider laterally-loaded pile in multi-layered soil in Fig. 3. A pile of length $L_{p}=20 \mathrm{~m}$, radius $r_{p}=$ $0.3 \mathrm{~m}$, and elastic modulus $E_{p}=25 \cdot 10^{6} \mathrm{kNm}^{2}$ is subjected to a lateral force $F=300 \mathrm{kN}$ and bending moment $M=100 \mathrm{kNm}$ at the pile head. The soil deposit has four layers with the bottom of the fourth layer extending to infinity downward. The thickness of the three-first layer is $5 \mathrm{~m}$. Finite element formulation based on the modified Vlasov foundation model [36] is utilized to calculate structural responses. Two-parameter of each layer consist of the compression foundation $k_{s}$ and the shear foundation $k_{t}$, with soil parameters of two upper layers, are triangular fuzzy numbers while remaining layers are deterministic values.

Require determine fuzzy horizontal displacement $u_{h}$ and fuzzy rotation displacement $\theta_{h}$ at pile head in two cases:

- case 1: $k_{\mathrm{s} 1}=(56.0,22.4,22.4)_{L R} \mathrm{MPa}, k_{\mathrm{t} 1}=(11.0,8.8,8.8)_{L R} \mathrm{MN}, k_{\mathrm{s} 2}=(140.0,56,56)_{L R} \mathrm{MPa}$, $k_{\mathrm{t} 2}=(56.0,22.4,22.4)_{L R} \mathrm{MN}, k_{\mathrm{s} 3}=155 \mathrm{MPa}, k_{\mathrm{t} 3}=80 \mathrm{MN}, k_{\mathrm{s} 4}=200 \mathrm{MPa}, k_{\mathrm{t} 4}=120 \mathrm{MN}$,

- case 2: $k_{\mathrm{s} 1}=(56,10,30)_{L R} \mathrm{MPa}, k_{\mathrm{t} 1}=(11,3,9)_{L R} \mathrm{MN}, k_{\mathrm{s} 2}=(140,70,70)_{L R} \mathrm{MPa}, k_{\mathrm{t} 2}=(56,28$, 28) $)_{L R} \mathrm{MN}, k_{\mathrm{s} 3}=155 \mathrm{MPa}, k_{\mathrm{t} 3}=80 \mathrm{MN}, k_{\mathrm{s} 4}=200 \mathrm{MPa}, k_{\mathrm{t} 4}=120 \mathrm{MN}$.

In this example, forty equal elements are utilized to compute the finite element solutions. Tables 1 and 2 show the results of fuzzy horizontal displacement at the pile head $u_{h}$ using the proposed method and the a-optimization method. To verify the accuracy of the proposed algorithm, differences 
between the results of the proposed algorithm and ones of the $\alpha$-optimization method are also calculated in these tables, including percentage errors in the lower bound, the upper bound, and the width of solutions. Membership functions of fuzzy horizontal displacement $u_{h}$ and fuzzy rotation displacement $\theta_{h}$, which are calculated by the proposed algorithm, the a-optimization method, and the non-complete quadratic polynomial regression model, are depicted in Fig. 4 and Fig. 5 respectively.

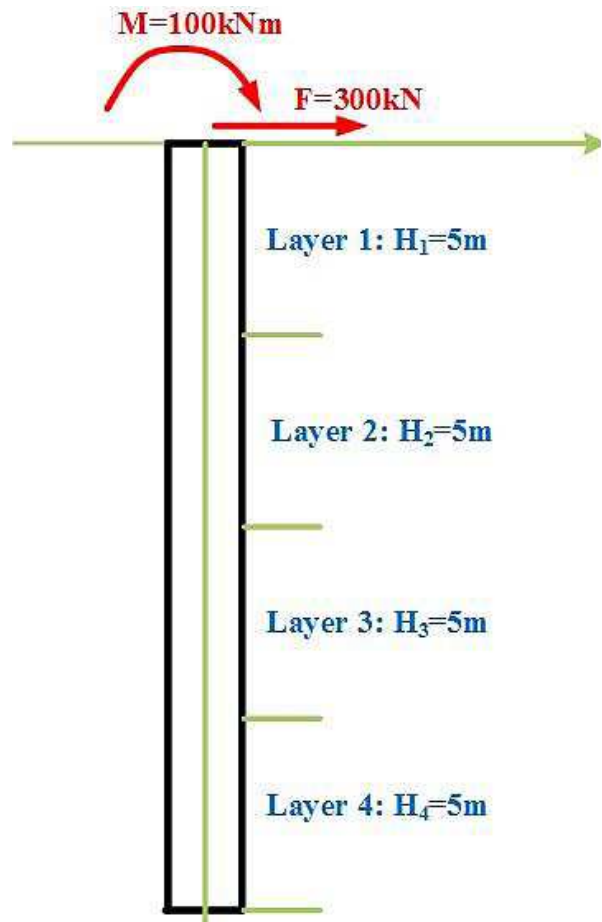

Layer 4

Fig. 3: Laterally-loaded pile in multi-layered soil.

Table 1: Fuzzy horizontal displacement $u_{h}$ in case 1.

\begin{tabular}{|c|c|c|c|c|c|c|c|}
\hline \multirow{2}{*}{$\alpha$-cuts } & \multicolumn{2}{|c|}{ The proposed algorithm } & \multicolumn{2}{|c|}{ The $\alpha$-optimization method } & \multirow{2}{*}{$\begin{array}{c}\text { Error LB } \\
{[\%]}\end{array}$} & \multirow{2}{*}{$\begin{array}{c}\text { Error UB } \\
\text { [\%] }\end{array}$} & \multirow{2}{*}{$\begin{array}{c}\text { Error width } \\
\text { [\%] }\end{array}$} \\
\hline & Lower [mm] & Upper [mm] & Lower [mm] & Upper [mm] & & & \\
\hline 0.0 & 4.5327 & 8.6404 & 4.4870 & 8.6981 & 1.02 & 0.66 & \multirow{6}{*}{2.46} \\
\hline 0.2 & 4.6777 & 7.9634 & 4.7010 & 7.8964 & 0.50 & 0.85 & \\
\hline 0.4 & 4.8816 & 7.3457 & 4.9385 & 7.2422 & 1.15 & 1.43 & \\
\hline 0.6 & 5.1446 & 6.7872 & 5.2059 & 6.7007 & 1.18 & 1.29 & \\
\hline 0.8 & 5.4667 & 6.2879 & 5.5054 & 6.2418 & 0.70 & 0.74 & \\
\hline 1.0 & 5.8478 & 5.8478 & 5.8478 & 5.8478 & 0.00 & 0.00 & \\
\hline
\end{tabular}

Table 2: Fuzzy horizontal displacement $u_{h}$ in case 2.

\begin{tabular}{|c|c|c|c|c|c|c|c|}
\hline \multirow{2}{*}{$\alpha$-cuts } & \multicolumn{2}{|c|}{ The proposed algorithm } & \multicolumn{2}{|c|}{ The $\alpha$-optimization method } & \multirow{2}{*}{$\begin{array}{c}\text { Error LB } \\
\text { [\%] }\end{array}$} & \multirow{2}{*}{$\begin{array}{c}\text { Error UB } \\
{[\%]}\end{array}$} & \multirow{2}{*}{$\begin{array}{c}\text { Error width } \\
{[\%]}\end{array}$} \\
\hline & Lower [mm] & Upper [mm] & Lower [mm] & Upper [mm] & & & \\
\hline 0.0 & 4.5918 & 7.4642 & 4.4868 & 7.3831 & 2.34 & 1.10 & \multirow{6}{*}{0.82} \\
\hline 0.2 & 4.7435 & 7.2044 & 4.7525 & 7.1343 & 0.19 & 0.98 & \\
\hline 0.4 & 4.9907 & 6.9587 & 5.0563 & 6.9045 & 1.30 & 0.79 & \\
\hline 0.6 & 5.3335 & 6.7272 & 5.4073 & 6.6911 & 1.36 & 0.54 & \\
\hline 0.8 & 5.7719 & 6.5099 & 5.8182 & 6.4920 & 0.80 & 0.27 & \\
\hline 1.0 & 6.3067 & 6.3067 & 6.3067 & 6.3067 & 0.00 & 0.00 & \\
\hline
\end{tabular}



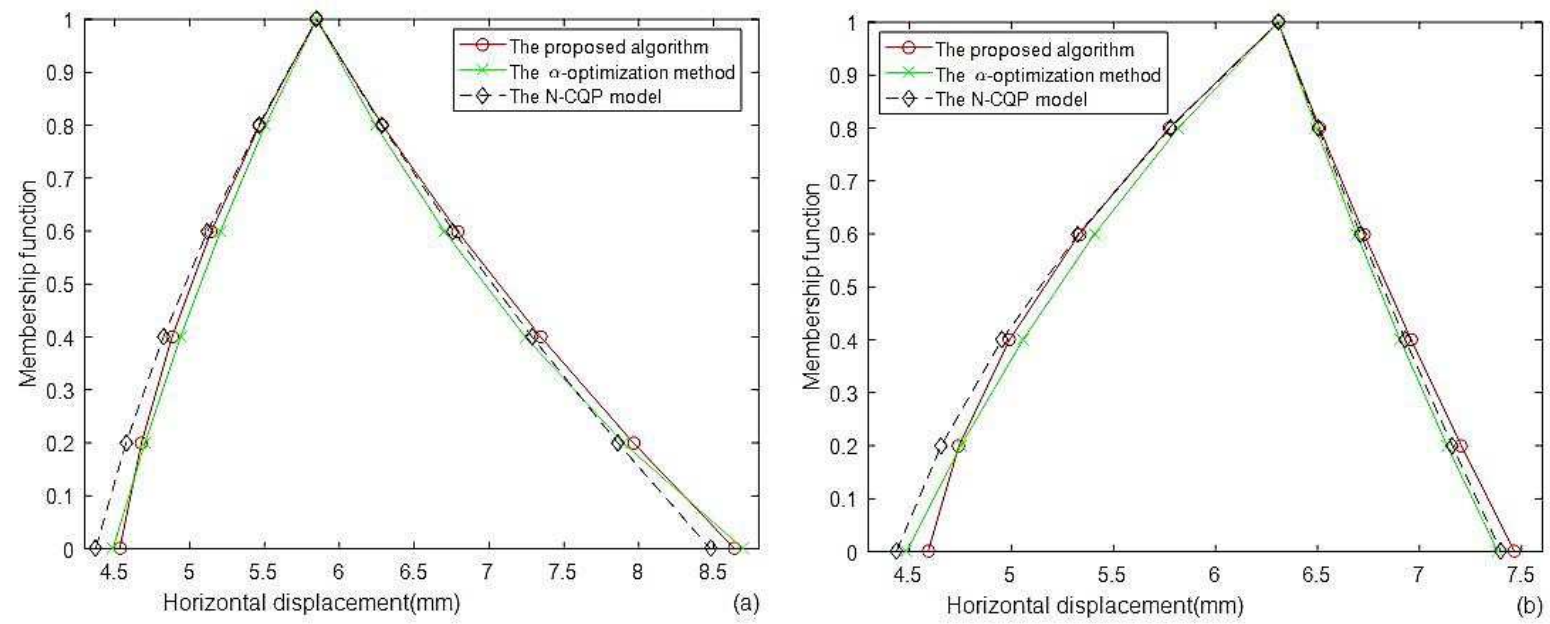

Fig. 4: Fuzzy horizontal displacement $u_{h}$ : a) case 1 and b) case 2.
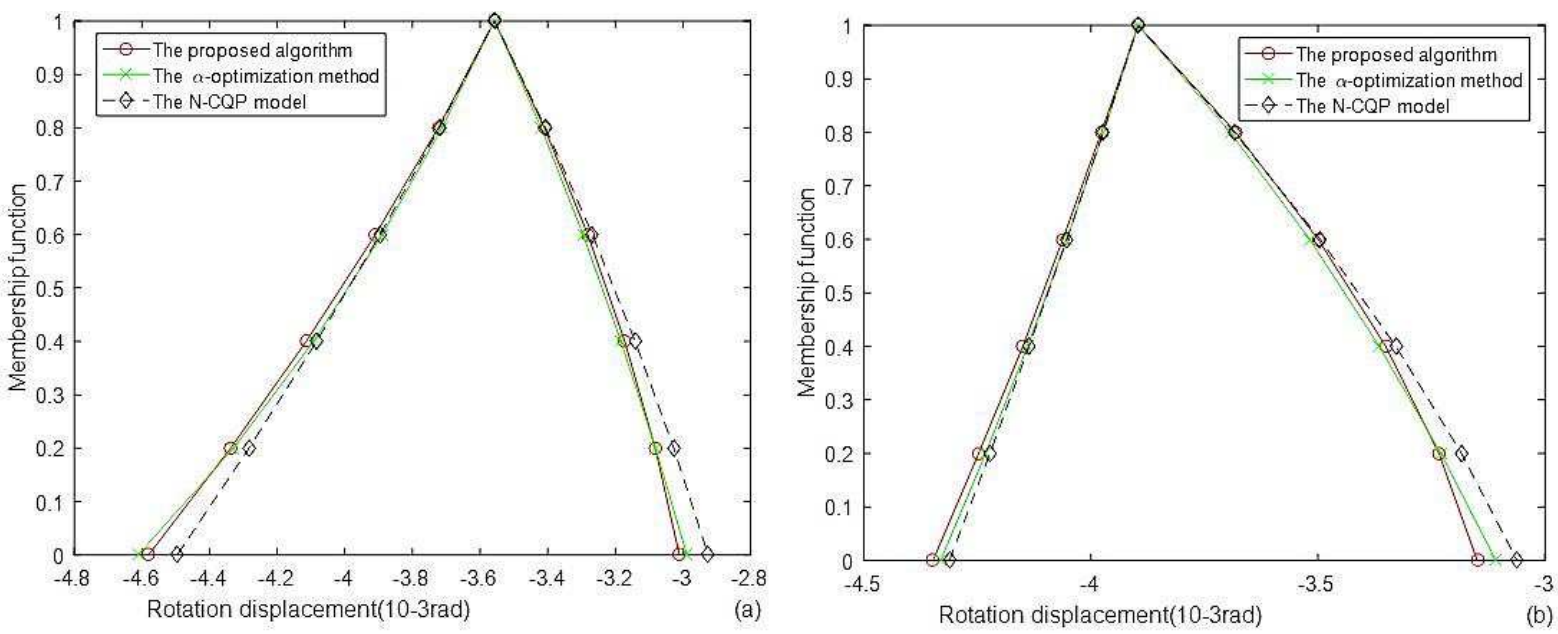

Fig. 5: Fuzzy rotation displacement $\theta_{h}$ : a) case and b) case 2 .

\subsection{Example 2}

Consider an eleven-bar plane truss in Fig. 6. The cross-sectional area of each bar is a certain variable of $0.01 \mathrm{~m}^{2}$. The elastic modulus $E$ and the load $P$ are triangular fuzzy numbers: $E=$ $(200,10,10)_{L R} \mathrm{GPa} ; P=(10,10,30)_{L R} \mathrm{kN}$.

Require: determine fuzzy axial forces of all bars in the system.

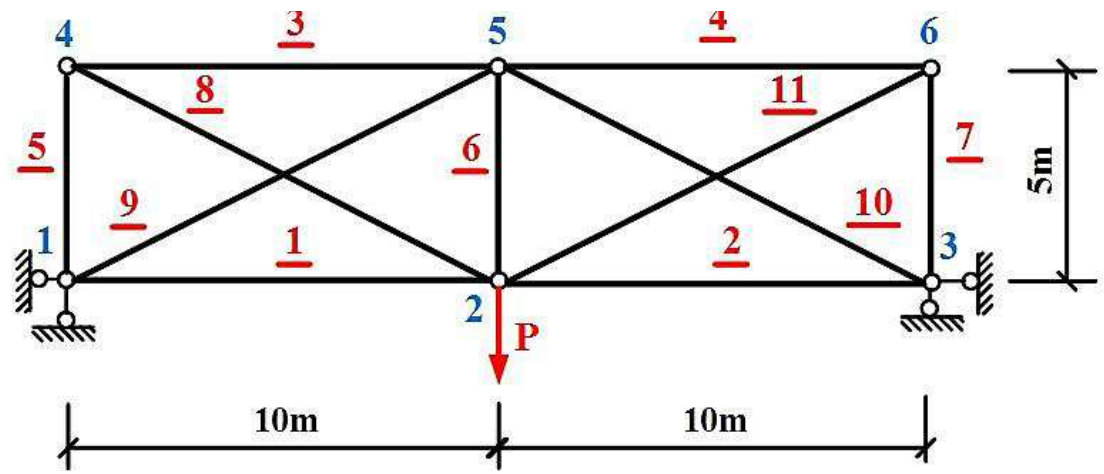

Fig. 6: Eleven-bar plane truss.

Because the problem contains two fuzzy variables, so the central composite design [29] is utilized in the proposed algorithm.

Applying the force method, the axial forces are given as follows 
$N_{1}=N_{2}=0 ; \quad N_{3}=N_{2}=-0.39509 P ; \quad N_{5}=N_{7}=-0.19755 P ;$

$N_{6}=0.60491 P ; \quad N_{8}=N_{11}=0.44172 P ; \quad N_{9}=N_{10}=-0.67631 P$.

Table 3 shows the marginals of fuzzy axial forces at membership level $\alpha=0$, using the proposed algorithm according to the formulae (17) and (18), the extension principle [1] for the formula (19). In this example, the results of the proposed algorithm according to the formulae (17), (18), and the formula (19) are the same ones of the complete quadratic polynomial regression model and the extension principle, respectively. Membership functions of fuzzy axial forces $N_{8}, N_{9}$ are depicted in Figs. 7 and 8.

Table 3: Marginals of fuzzy axial forces at membership level $\alpha=0$.

\begin{tabular}{|c|c|c|}
\hline $\begin{array}{c}\text { Axial force } \\
{[\mathbf{k N}]}\end{array}$ & $\begin{array}{c}\text { The proposed algorithm according to } \\
\text { the formulae (17) and (18) }\end{array}$ & $\begin{array}{c}\text { The extension principle for } \\
\text { the formula (19) }\end{array}$ \\
\hline$N_{1}=N_{2}$ & {$[0,0]$} & {$[0,0]$} \\
\hline$N_{3}=N_{4}$ & {$[-15.8200,0.0076]$} & {$[-15.8034,0]$} \\
\hline$N_{5}=N_{7}$ & {$[0,7.9099]$} & {$[0,7.9018]$} \\
\hline$N_{6}$ & {$[0,24.2221]$} & {$[0,24.1964]$} \\
\hline$N_{8}=N_{11}$ & {$[-0.0085,17.6873]$} & {$[0,17.6688]$} \\
\hline$N_{9}=N_{10}$ & {$[-27.0809,0.0130]$} & {$[-27.0523,0]$} \\
\hline
\end{tabular}

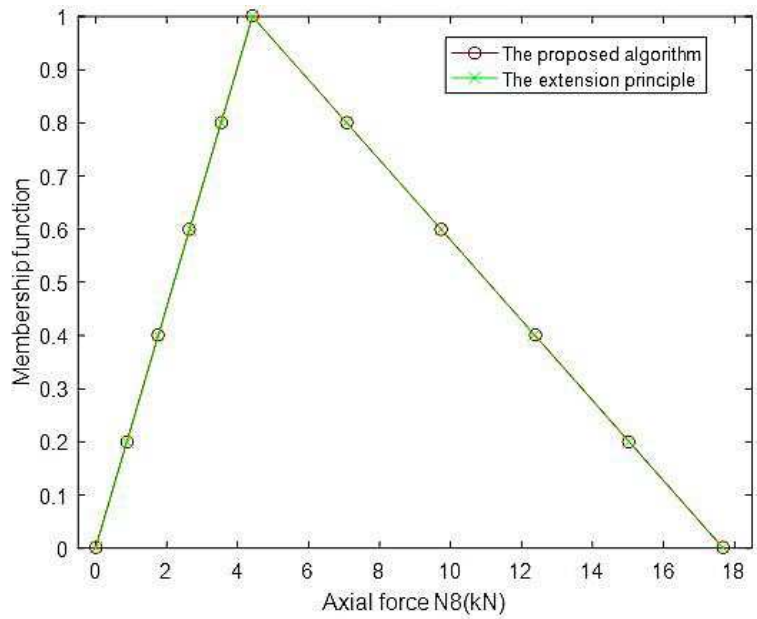

Fig. 7: Fuzzy axial force $N_{8}$.

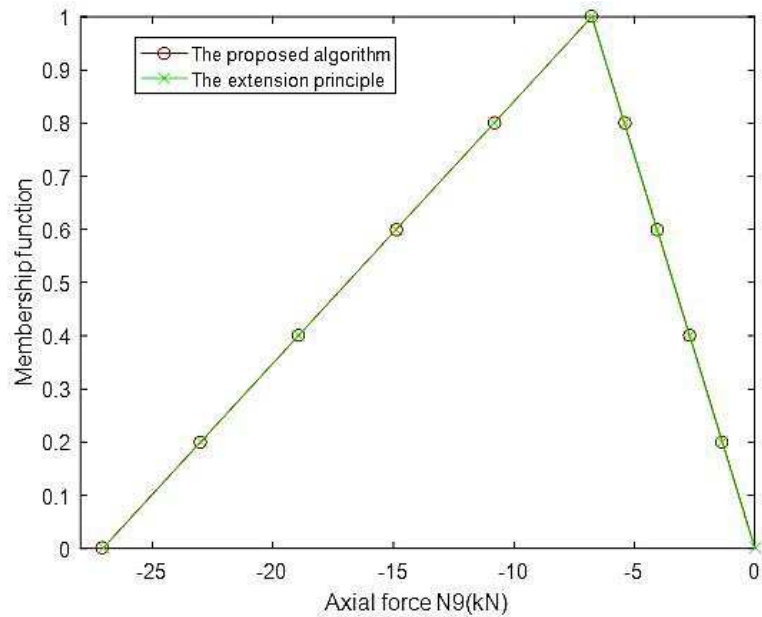

Fig. 8: Fuzzy axial force $N_{9}$.

\subsection{Example 3}

Consider a fifteen-bar plane truss in Fig. 9. The cross-sectional area of elements 1, 2, 3, 13, 14, 15 is a certain variable of $0.01 \mathrm{~m}^{2}$, and one of all other elements is of $0.006 \mathrm{~m}^{2}$. The elastic modulus $E$ and the loads $P_{1}, P_{2}, P_{3}, P_{4}$ are symmetric triangular fuzzy numbers: $E=(200,20,20)_{L R} G P a, P_{1}=$ $(200,20,20)_{L R} \mathrm{kN}, P_{2}=(100,10,10)_{L R} \mathrm{kN}, P_{3}=(100,10,10)_{L R} \mathrm{kN}, P_{4}=(90,9,9)_{L R} \mathrm{kN}$.

Require determine fuzzy axial forces of all bars in the system.

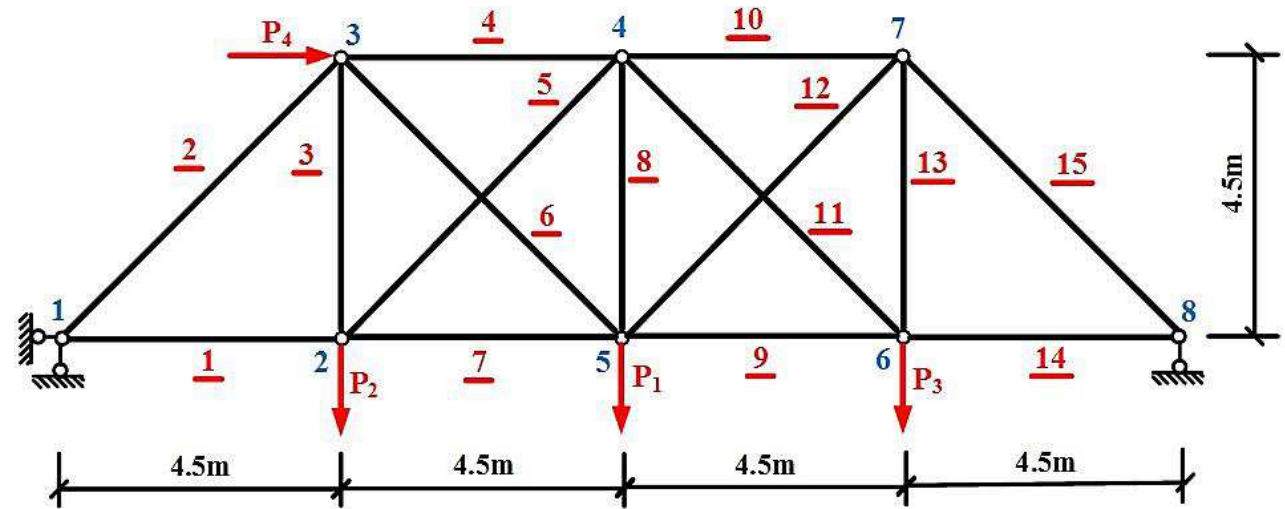

Fig. 9: Fifteen-bar plane truss. 
One realizes that in this example, the fuzzy total stiffness matrix $\widetilde{\mathbf{K}}$ can be represented as the formula (16). Hence, the formulae (17) and (18) should be applied to calculate the fuzzy axial forces. The result of fuzzy axial force $N_{13}$, which has the largest percentage error in the width of solutions between the proposed algorithm using the formulae (17), (18) and the a-optimization method, is shown in Table 4. Table 5 shows marginals of fuzzy axial forces $N_{i}$ at membership level $\alpha=0$, using the proposed algorithm and the $\alpha$-optimization method. Membership functions of the fuzzy axial forces $N_{5}, N_{8}, N_{11}, N_{13}$ are depicted in Figs. $10-13$ respectively.

Table 4: The result of fuzzy force $N_{13}$ using the proposed algorithm and the a-optimization method.

\begin{tabular}{|c|c|c|c|c|c|c|c|}
\hline \multirow{2}{*}{$\alpha$-cuts } & \multicolumn{2}{|c|}{$\begin{array}{c}\text { The proposed algorithm using } \\
\text { the formulae (17), (18) }\end{array}$} & \multicolumn{2}{|c|}{ The $\alpha$-optimization method } & \multirow{2}{*}{$\begin{array}{l}\text { Error LB } \\
{[\%]}\end{array}$} & \multirow{2}{*}{$\begin{array}{l}\text { Error UB } \\
{[\%]}\end{array}$} & \multirow{2}{*}{$\begin{array}{c}\text { Error width } \\
\text { [\%] }\end{array}$} \\
\hline & Lower [kN] & Upper [kN] & Lower [kN] & Upper [kN] & & & \\
\hline 0.0 & 127.7177 & 153.6391 & 127.7177 & 156.0991 & 0.00 & 1.58 & \multirow{6}{*}{8.67} \\
\hline 0.2 & 130.5558 & 151.2929 & 130.5558 & 153.2610 & 0.00 & 1.28 & \\
\hline 0.4 & 133.3939 & 148.9468 & 133.3939 & 150.4228 & 0.00 & 0.98 & \\
\hline 0.6 & 136.2321 & 146.6006 & 136.2321 & 147.5846 & 0.00 & 0.67 & \\
\hline 0.8 & 139.0702 & 144.2545 & 139.0702 & 144.7465 & 0.00 & 0.34 & \\
\hline 1.0 & 141.9083 & 141.9083 & 141.9083 & 141.9083 & 0.00 & 0.00 & \\
\hline
\end{tabular}

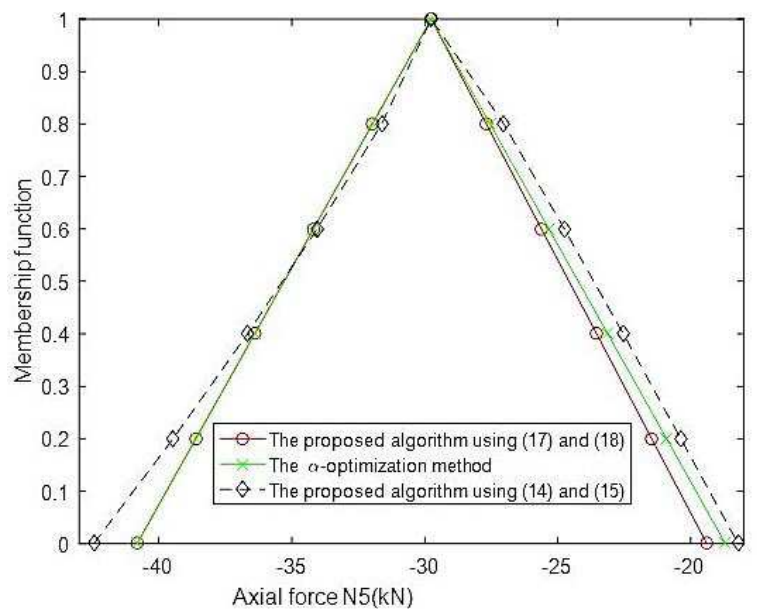

Fig. 10: Fuzzy axial force $N_{5}$.

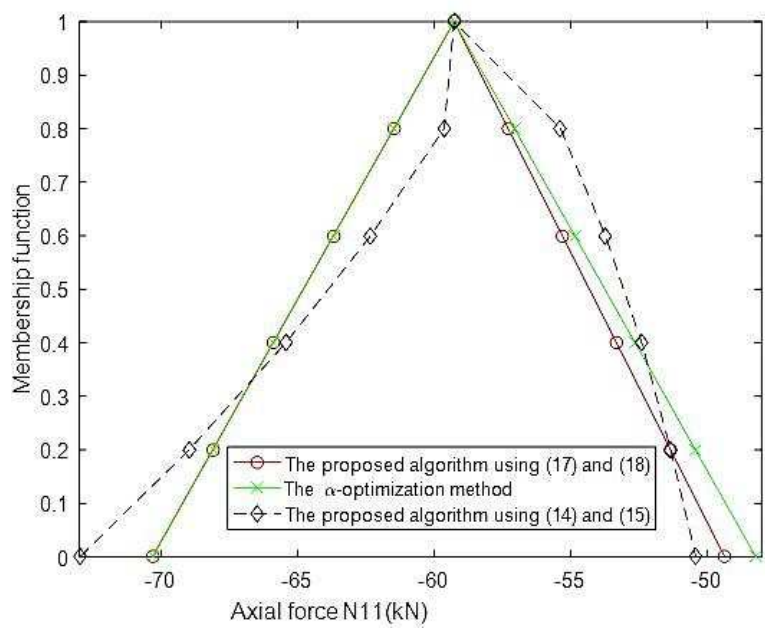

Fig. 12: Fuzzy axial force $N_{11}$.

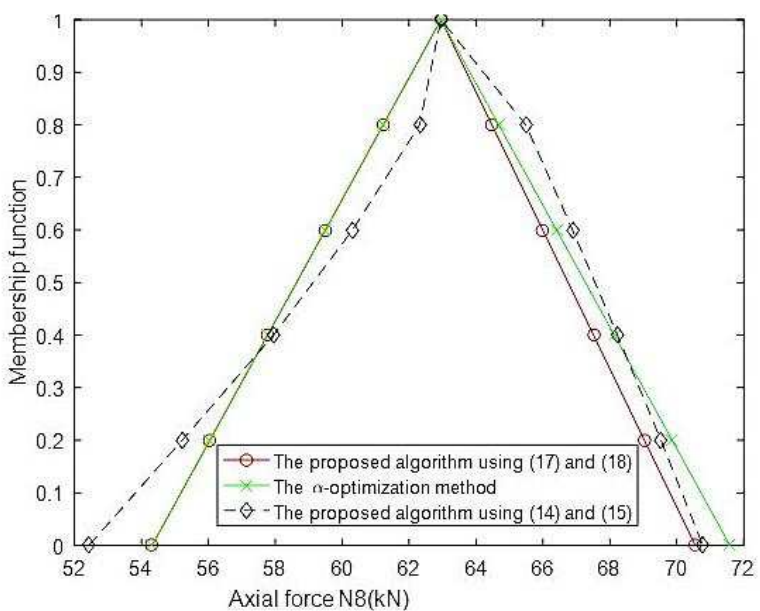

Fig. 11: Fuzzy axial force $N_{8}$.

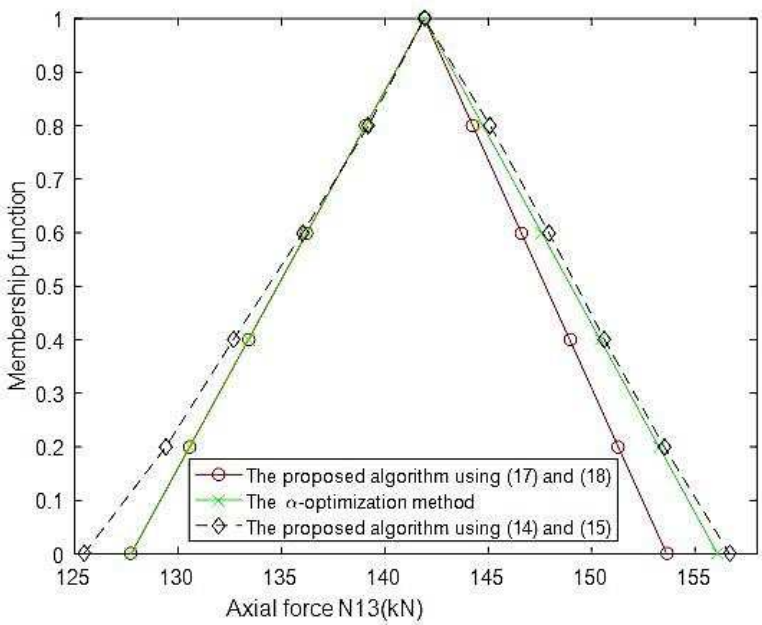

Fig. 13: Fuzzy axial force $N_{13}$. 
Table 5: Marginals of fuzzy axial forces at membership level $\alpha=0$.

\begin{tabular}{|c|c|c|c|}
\hline $\begin{array}{c}\text { Axial force } \\
{[\mathbf{k N}]}\end{array}$ & $\begin{array}{c}\text { The proposed algorithm using } \\
\text { the formulae (17), (18) }\end{array}$ & $\begin{array}{c}\text { The proposed algorithm using the } \\
\text { formulae (12), (14), (15) }\end{array}$ & The $\boldsymbol{\alpha}$-optimization method \\
\hline$N_{1}$ & {$[237.6590,294.7679]$} & {$[240.7502,294.2500]$} & {$[240.7502,294.2500]$} \\
\hline$N_{2}$ & {$[-283.1009,-220.6933]$} & {$[-284.4892,-219.5571]$} & {$[-284.4892,-219.5570]$} \\
\hline$N_{3}$ & {$[108.1996,136.9573]$} & {$[107.7212,135.2341]$} & {$[106.8525,135.2341]$} \\
\hline$N_{4}$ & {$[-353.2004,-285.9976]$} & {$[-356.3524,-291.5618]$} & {$[-356.3524,-291.5618]$} \\
\hline$N_{5}$ & {$[-42.4439,-18.2228]$} & {$[-40.8200,-19.3980]$} & {$[-40.8200,-18.6994]$} \\
\hline$N_{6}$ & {$[66.1074,96.8557]$} & {$[66.9154,93.1767]$} & {$[66.5070,93.1767]$} \\
\hline$N_{7}$ & {$[260.5507,321.7632]$} & {$[259.6898,317.3976]$} & {$[259.6898,317.3976]$} \\
\hline$N_{8}$ & {$[52.4304,70.7781]$} & {$[54.3166,70.5581]$} & {$[54.3166,71.5866]$} \\
\hline$N_{9}$ & {$[234.6004,290.3413]$} & {$[237.9694,290.8491]$} & {$[237.9677,290.8491]$} \\
\hline$N_{10}$ & {$[-336.0867,-275.4615]$} & {$[-333.4009,-272.7832]$} & {$[-333.4009,-272.7833]$} \\
\hline$N_{11}$ & {$[-72.9843,-50.4060]$} & {$[-70.3276,-49.3469]$} & {$[-70.3276,-48.2071]$} \\
\hline$N_{12}$ & {$[99.0911,128.0751]$} & {$[100.6391,127.3088]$} & {$[100.6391,127.3088]$} \\
\hline$N_{13}$ & {$[125.4396,156.6791]$} & {$[127.7177,153.6391]$} & {$[127.7177,156.0991]$} \\
\hline$N_{14}$ & {$[196.4112,241.8909]$} & {$[200.2503,244.7500]$} & {$[200.2503,244.7500]$} \\
\hline$N_{15}$ & {$[-346.6271,-285.6186]$} & {$[-346.1288,-283.2008]$} & {$[-346.1288,-283.2008]$} \\
\hline
\end{tabular}

\subsection{Example 4}

Consider a three-story, two-bay plane frame in Fig. 14. The cross-section of all elements is a rectangle. The width $b_{b}$, the height $h_{b}$ of all beams are certain variables of $0.2 \mathrm{~m}$ and $0.5 \mathrm{~m}$, respectively. The width $b_{c}$ of all columns is a certain variable of $0.2 \mathrm{~m}$. The elastic modulus $E$, the uniform load $q$, the concentrated load $P$ and the height $h_{c}$ of all columns are triangular fuzzy numbers: $E=(30,3,3)_{L R} \mathrm{GPa}, q=(25,1,4)_{L R} \mathrm{kN} / \mathrm{m}, P=(30,4,2)_{L R} \mathrm{kN}, h_{C}=(0.3,0.02,0.02)_{L R} \mathrm{~m}$.

Require: determine fuzzy horizontal displacement at the top of the plane frame and fuzzy internal forces of all columns.

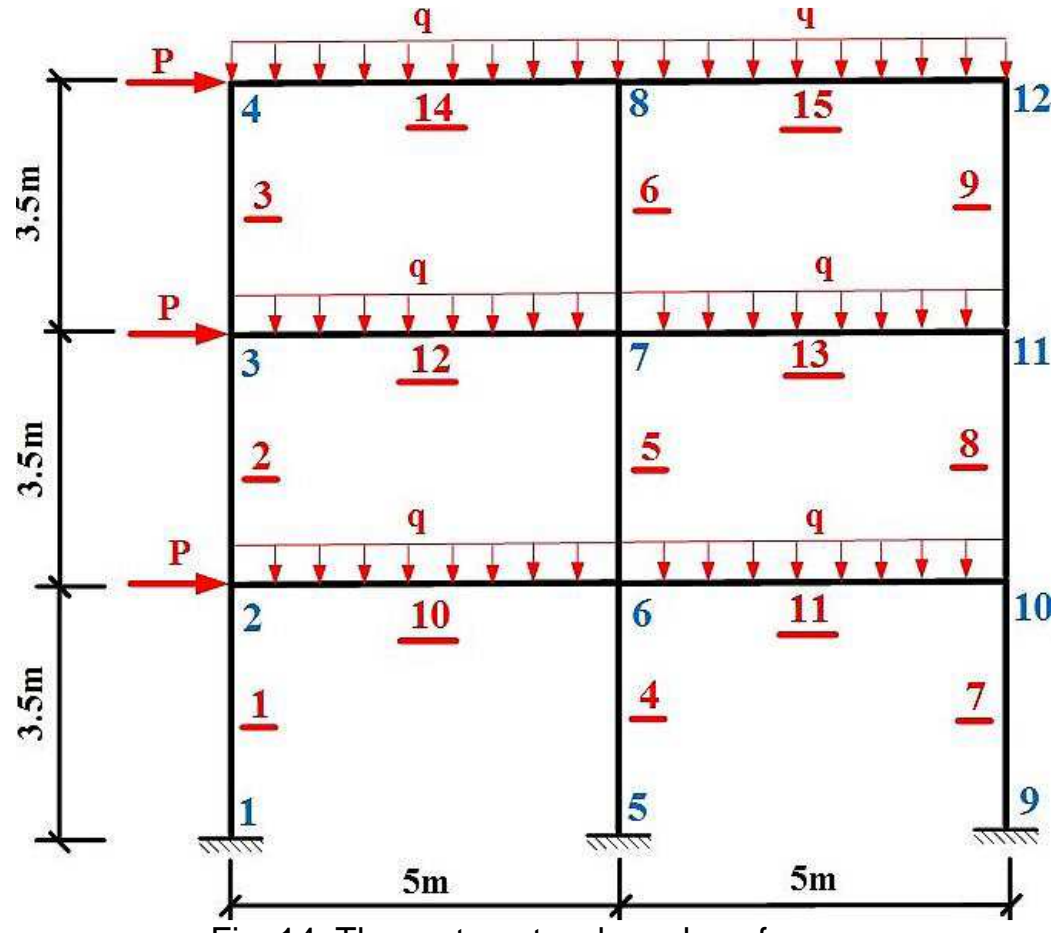

Fig. 14: Three-story, two-bay plane frame.

One realizes that the fuzzy variables have widely divergent domains. Hence, the significant overestimations for fuzzy responses of structures are obtained by using the original fuzzy variables. The proposed method is utilized to overcome this drawback. 
Table 6 shows the results of fuzzy horizontal displacement at the top of the plane frame using the proposed algorithm and the $\alpha$-optimization method. Membership function of fuzzy horizontal displacement at the top of the plane frame $u_{t}$, which is calculated by the proposed algorithm, the $\alpha$ optimization method, and the non-complete quadratic polynomial regression model, are depicted in Fig. 15.

Tables 7, 8, 9 show marginals of fuzzy axial forces $N_{m}$, fuzzy shear forces $Q_{m}$, and fuzzy bending moments $M_{i j}$ at membership level $\alpha=0$, using the proposed algorithm and the $\alpha$-optimization method, respectively. Membership functions of fuzzy internal forces of element 6 , which have the largest percentage errors of solutions between the proposed algorithm and the $\alpha$-optimization method, are depicted in Fig. 16.

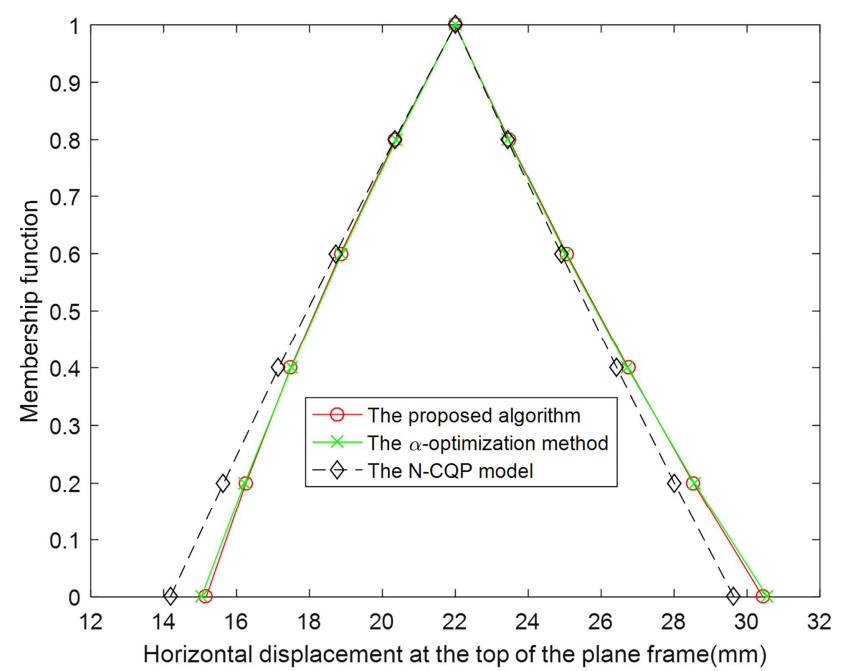

Fig. 15: Fuzzy horizontal displacement at the top of the plane frame $u_{t}$.

Table 6: Fuzzy horizontal displacement at the top of the plane frame $u_{t}$

\begin{tabular}{|c|c|c|c|c|c|c|c|}
\hline \multirow{2}{*}{$\alpha$-cuts } & \multicolumn{2}{|c|}{ The proposed algorithm } & \multicolumn{2}{|c|}{ The $\alpha$-optimization method } & $\begin{array}{c}\text { Error LB } \\
\text { [\%] }\end{array}$ & $\begin{array}{c}\text { Error UB } \\
\text { [\%] }\end{array}$ & $\begin{array}{c}\text { Error with } \\
\text { [\%] }\end{array}$ \\
\cline { 2 - 7 } & Lower [mm] & Upper [mm] & Lower [mm] & Upper [mm] & 0.8820 & 0.3999 & \\
\hline 0.0 & 15.1675 & 30.4373 & 15.0349 & 30.5595 & 0.2304 & 0.0909 \\
\hline 0.2 & 16.2580 & 28.5332 & 16.2206 & 28.5592 & 0.075 & \multirow{2}{*}{1.6413} \\
\hline 0.4 & 17.4866 & 26.7376 & 17.5005 & 26.7173 & 0.0796 & 0.0758 \\
\hline 0.8 & 18.8533 & 25.0502 & 18.8837 & 25.0190 & 0.1608 & 0.1246 \\
\hline 1.0 & 20.3581 & 23.4714 & 20.3802 & 23.4509 & 0.1082 & 0.0876 \\
\hline
\end{tabular}

Table 7: Marginals of fuzzy axial forces at membership level $\alpha=0$.

\begin{tabular}{|c|c|c|c|}
\hline Element & Axial force $\boldsymbol{N}_{\boldsymbol{m}}[\mathbf{k N}]$ & The proposed algorithm & The $\boldsymbol{\alpha}$-optimization method \\
\hline 1 & $N_{1}$ & {$[109.1898,156.8777]$} & {$[109.1359,156.3604]$} \\
\hline 2 & $N_{2}$ & {$[83.2745,112.5532]$} & {$[83.3655,112.6041]$} \\
\hline 3 & $N_{3}$ & {$[45.6757,58.9773]$} & {$[45.5067,58.4313]$} \\
\hline 4 & $N_{4}$ & {$[395.1228,487.1164]$} & {$[395.3570,486.8912]$} \\
\hline 5 & $N_{5}$ & {$[262.7032,323.3509]$} & {$[262.8042,323.5043]$} \\
\hline 6 & $N_{6}$ & {$[134.8515,165.8160]$} & {$[135.0182,165.5598]$} \\
\hline 7 & $N_{7}$ & {$[198.1185,244.9262]$} & {$[198.6562,245.1023]$} \\
\hline 8 & $N_{8}$ & {$[124.9337,154.4760]$} & {$[124.6389,154.1343]$} \\
\hline 9 & $N_{9}$ & {$[56.1345,69.8872]$} & {$[56.3563,69.5745]$} \\
\hline
\end{tabular}


Table 8: Marginals of fuzzy shear forces at membership level $\alpha=0$.

\begin{tabular}{|c|c|c|c|}
\hline Element & Shear force $\left.\boldsymbol{Q}_{\boldsymbol{m}} \mathbf{[ k N}\right]$ & The proposed algorithm & The $\boldsymbol{\alpha}$-optimization method \\
\hline 1 & $Q_{1}$ & {$[18.5841,26.4443]$} & {$[18.5926,26.4374]$} \\
\hline 2 & $Q_{2}$ & {$[3.6883,11.0087]$} & {$[3.6908,10.9993]$} \\
\hline 3 & $Q_{3}$ & {$[-6.0018,0.3152]$} & {$[-6.0222,0.3374]$} \\
\hline 4 & $Q_{4}$ & {$[28.9492,36.3193]$} & {$[28.9272,36.3452]$} \\
\hline 5 & $Q_{5}$ & {$[21.8660,27.9955]$} & {$[21.8576,28.0000]$} \\
\hline 6 & $Q_{6}$ & {$[10.9104,14.0793]$} & {$[10.9296,14.0580]$} \\
\hline 7 & $Q_{7}$ & {$[28.3190,35.4304]$} & {$[28.3111,35.4506]$} \\
\hline 8 & $Q_{8}$ & {$[22.6361,28.9058]$} & {$[22.6194,28.9375]$} \\
\hline 9 & $Q_{9}$ & {$[16.5798,22.3345]$} & {$[16.4720,22.2820]$} \\
\hline
\end{tabular}

Table 9: Marginals of fuzzy bending moments at membership level $\alpha=0$.

\begin{tabular}{|c|c|c|c|}
\hline Element & Bending moment $M_{i j}[\mathrm{kNm}]$ & The proposed algorithm & The $\alpha$-optimization method \\
\hline \multirow{2}{*}{1} & $M_{12}$ & {$[40.7250,52.9764]$} & {$[40.7856,52.9255]$} \\
\hline & $M_{21}$ & {$[24.2696,39.6200]$} & {$[24.2885,39.6056]$} \\
\hline \multirow{2}{*}{2} & $M_{23}$ & {$[4.3211,17.4922]$} & {$[4.3239,17.4756]$} \\
\hline & $M_{32}$ & {$[8.5881,21.0384]$} & {$[8.5939,21.0220]$} \\
\hline \multirow{2}{*}{3} & $M_{34}$ & {$[-10.5788,-0.2024]$} & {$[-10.6127,-0.1439]$} \\
\hline & $M_{43}$ & {$[-10.4281,1.2844]$} & {$[-10.4650,1.3246]$} \\
\hline \multirow{2}{*}{4} & $M_{56}$ & {$[51.6904,65.8327]$} & {$[51.6496,65.8424]$} \\
\hline & $M_{65}$ & {$[49.6621,61.3728]$} & {$[49.5954,61.3658]$} \\
\hline \multirow{2}{*}{5} & $M_{67}$ & {$[38.0451,48.4826]$} & {$[38.0297,48.4877]$} \\
\hline & $M_{76}$ & {$[38.4859,49.4992]$} & {$[38.4719,49.5121]$} \\
\hline \multirow{2}{*}{6} & $M_{78}$ & {$[18.5813,23.5322]$} & {$[18.6187,23.4966]$} \\
\hline & $M_{87}$ & {$[19.6654,25.7624]$} & {$[19.6352,25.7063]$} \\
\hline \multirow{2}{*}{7} & $M_{910}$ & {$[50.9332,64.7389]$} & {$[50.9140,64.7696]$} \\
\hline & $M_{109}$ & {$[48.1833,59.3280]$} & {$[48.1750,59.3074]$} \\
\hline \multirow{2}{*}{8} & $M_{1011}$ & {$[38.2585,48.5399]$} & {$[38.2323,48.5952]$} \\
\hline & $M_{1110}$ & {$[40.9679,52.6306]$} & {$[40.9355,52.6860]$} \\
\hline \multirow{2}{*}{9} & $M_{1112}$ & {$[26.7921,35.1841]$} & {$[26.6300,35.1023]$} \\
\hline & $M_{1211}$ & {$[31.2423,42.9743]$} & {$[31.0219,42.8846]$} \\
\hline
\end{tabular}

In the previous examples, the fuzzy internal forces are formulated as a linear combination for the fuzzy loads. Hence, the a-optimization method yields the exact membership functions of the fuzzy internal forces. Different from the previous example, in this example, with the height of all columns is the fuzzy variable; the fuzzy internal forces are formulated not only as a linear combination for the fuzzy loads but also non-linear for the fuzzy height of all columns. In this context, the mapping model of the fuzzy input data into the fuzzy internal forces is not biunique, and the results obtaining by the $\alpha$ optimization method maybe not "exact". Owing to this reason, besides comparing the results of the proposed algorithm with ones of the a-optimization method, the equations of equilibrium of the upper segments at the pre-defined sections depicted in Fig. 17, and the similarity measure of fuzzy numbers [37] are applied to assess the accuracy of the proposed method, the complete and the non-complete quadratic polynomial regression model. For instance, the equations of equilibrium of the upper segment at I-I and IA-IA sections (Fig. 18) are given as follows

$$
\begin{aligned}
& \sum F_{x}=0 \Rightarrow Q_{3}+Q_{6}+Q_{9}=P, \\
& \sum F_{y}=0 \Rightarrow N_{3}+N_{6}+N_{9}=10_{q}, \\
& \sum M_{4}=0 \Rightarrow M_{1211}+M_{87}+M_{43}+50_{q}=10 N_{9}+5 N_{6},
\end{aligned}
$$




$$
\begin{aligned}
& \sum M_{8}=0 \Rightarrow M_{1211}+M_{87}+M_{43}+5 N_{3}=5 N_{9}, \\
& \sum M_{12}=0 \Rightarrow M_{1211}+M_{87}+M_{43}+5 N_{6}+10 N_{3}=50_{q}, \\
& \sum M_{3}=0 \Rightarrow M_{1112}+M_{78}+M_{34}+5 N_{6}+10 N_{9}=3.5 P+50_{q}, \\
& \sum M_{7}=0 \Rightarrow M_{1112}+M_{78}+M_{34}+5 N_{9}=3.5 P+5 N_{3}, \\
& \sum M_{11}=0 \Rightarrow M_{1112}+M_{78}+M_{34}+50_{q}=10 N_{3}+5 N_{6}+3.5 P,
\end{aligned}
$$
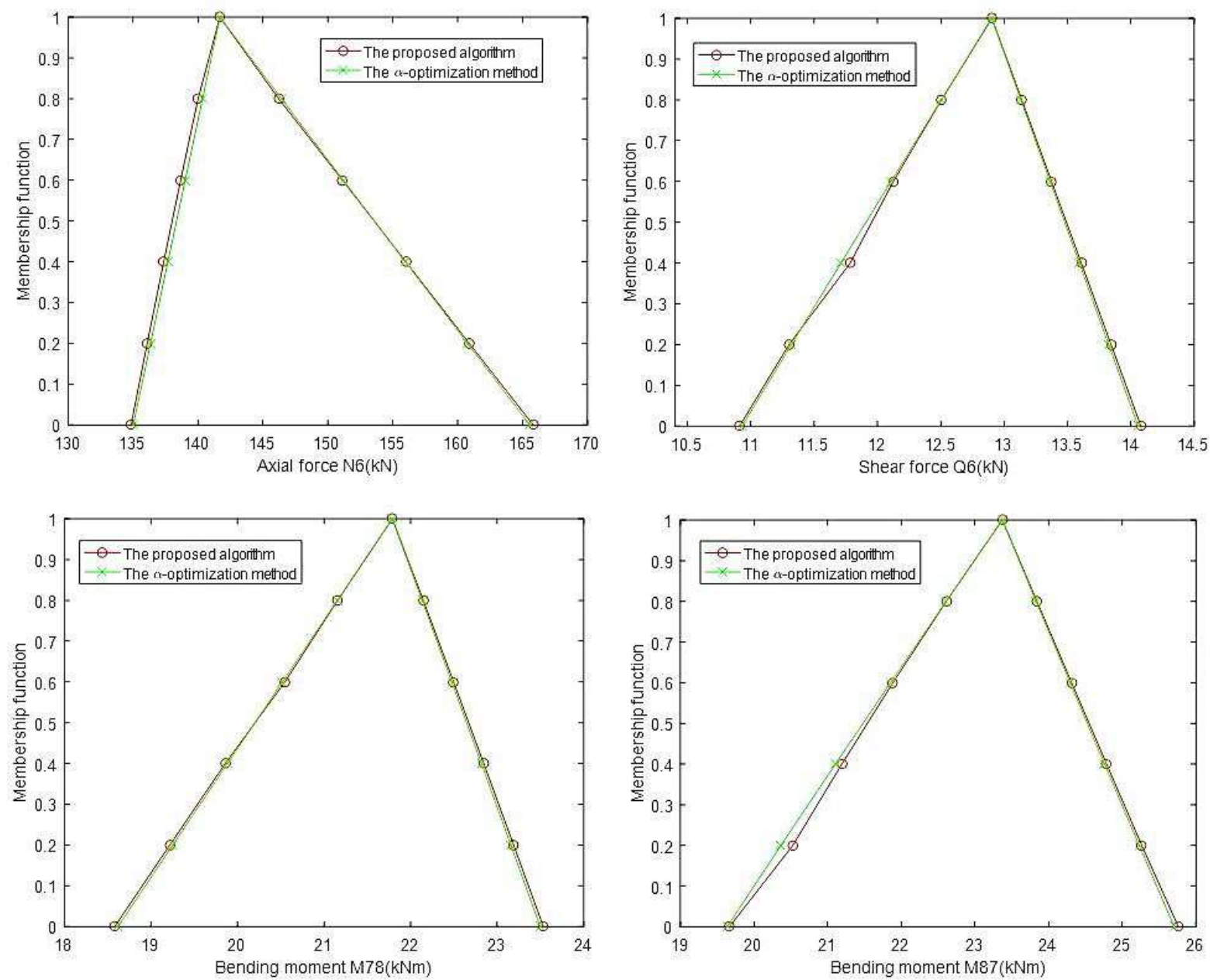

Fig. 16: Membership functions of fuzzy internal forces of element 6.

In classical mathematics, the equation (24) is a linear combination of equations (22) and (23). Similarly, equation (27) is a linear combination of equations (25) and (26). However, in fuzzy set theory, generally speaking, the left-hand side and the right-hand side of each above equation are not the same; they are similar to each other. Hence, the similarity measure between two fuzzy numbers, which are the left-hand side and the right-hand side of each equation of equilibrium, is utilized to compare the accuracy of the proposed algorithm, the complete and the non-complete quadratic polynomial regression model. For two fuzzy numbers $A$ and $B$, the degree of similarity $S(A, B)$ between fuzzy numbers $A$ and $B$ is expressed as follows [37]

$$
S(A, B)=\frac{\int(A \cap B) \mathrm{d} \alpha}{\int(A \cup B) \mathrm{d} \alpha} .
$$

The larger the value of $S(A, B)$, the more the similarity measure between two fuzzy numbers $A$ and $B$. The more similarity measure the method has, the better accuracy the method can get. 


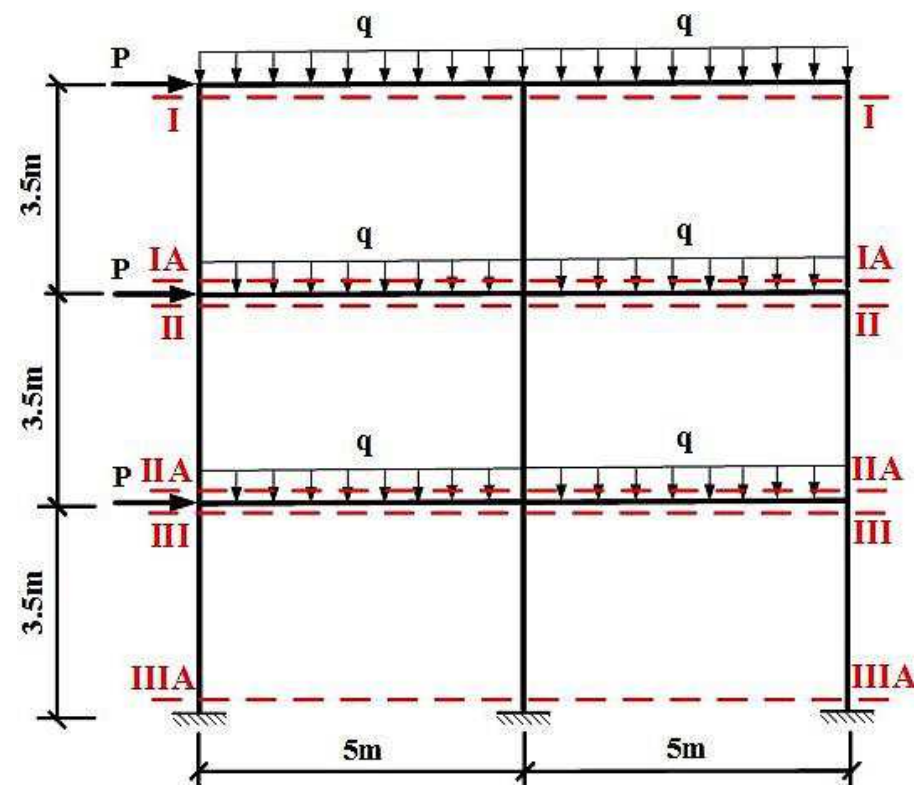

Fig. 17: The defined sections at the stories.

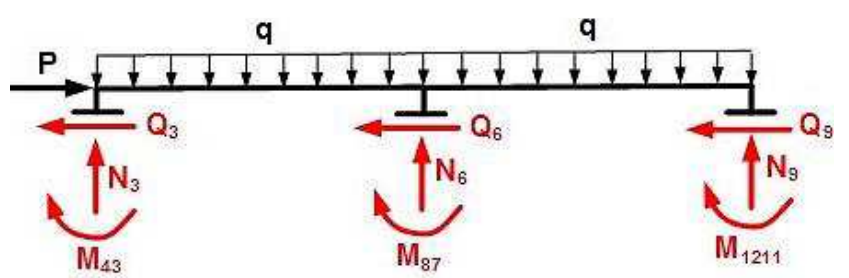

a. The free-body diagram of upper segment

at I-I section

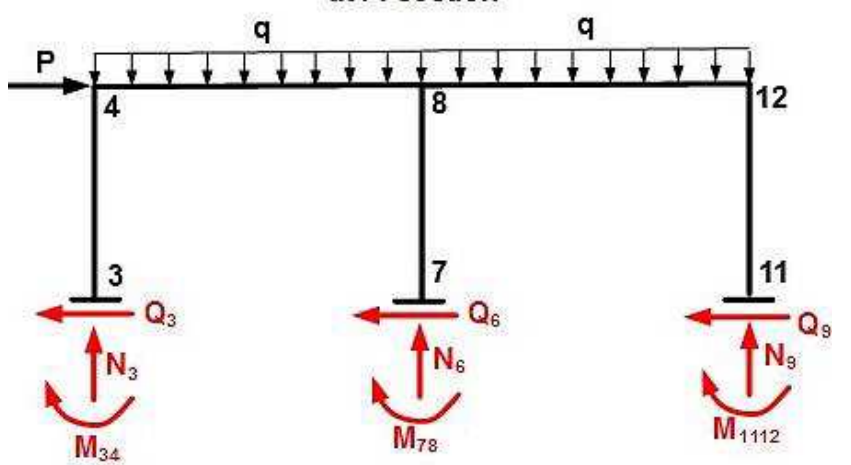

b. The free-body diagram of upper segment at

IA-IA section

Fig. 18: The free-body diagrams for the representative sections.

Tables 10 and 11 show the results of the similarity measures between the left-hand sides (LHSs) and the right-hand sides (RHSs) of the equations of equilibrium for forces and moments at the predefined sections. These results involve the proposed algorithm, the complete quadratic polynomial regression model, the non-complete quadratic polynomial regression model, and the $\alpha$-optimization method. 
Table 10: The similarity measures between the LHSs and RHSs of the equations of equilibrium for forces.

\begin{tabular}{|c|c|c|c|c|}
\hline \multirow{2}{*}{ Section/Direction } & \multicolumn{4}{|c|}{ The similarity measure } \\
\cline { 2 - 5 } & $\begin{array}{c}\text { The proposed } \\
\text { algorithm }\end{array}$ & $\begin{array}{c}\text { The complete quadratic } \\
\text { polynomial regression } \\
\text { model }\end{array}$ & $\begin{array}{c}\text { The non-complete } \\
\text { quadratic polynomial } \\
\text { regression model }\end{array}$ & $\begin{array}{c}\text { The } \alpha \text {-optimization } \\
\text { method }\end{array}$ \\
\hline I-I /X & 0.3952 & 0.3908 & 0.3705 & 0.3940 \\
\hline I-I/Y & 0.8633 & 0.8604 & 0.8091 & 0.8832 \\
\hline II-II/X & 0.6109 & 0.6065 & 0.5499 & 0.6082 \\
\hline II-II/Y & 0.8346 & 0.8322 & 0.7786 & 0.8386 \\
\hline III-III/X & 0.8016 & 0.8044 & 0.8008 & 0.6718 \\
\hline III-III/Y & 0.8043 & 0.8037 & 0.7506 & 0.8112 \\
\hline The average value & 0.7183 & 0.7157 & 0.6551 & 0.7233 \\
\hline
\end{tabular}

Table 11: The similarity measures between the LHSs and RHSs of the equations of equilibrium for moments.

\begin{tabular}{|c|c|c|c|c|}
\hline \multirow{2}{*}{ Section/Node } & \multicolumn{4}{|c|}{ The similarity measure } \\
\cline { 2 - 5 } & $\begin{array}{c}\text { The proposed } \\
\text { algorithm }\end{array}$ & $\begin{array}{c}\text { The complete quadratic } \\
\text { polynomial regression } \\
\text { model }\end{array}$ & $\begin{array}{c}\text { The non-complete } \\
\text { quadratic polynomial } \\
\text { regression model }\end{array}$ & $\begin{array}{c}\text { The } \alpha \text {-optimization } \\
\text { method }\end{array}$ \\
\hline I-I/4 & 0.7752 & 0.7726 & 0.7281 & 0.7959 \\
\hline I-I/8 & 0.7270 & 0.7224 & 0.7173 & 0.7014 \\
\hline I-I/12 & 0.7925 & 0.7882 & 0.7423 & 0.8035 \\
\hline II-II/3 & 0.9292 & 0.9249 & 0.8724 & 0.9307 \\
\hline II-II/7 & 0.7201 & 0.7272 & 0.7169 & 0.7286 \\
\hline II-II/11 & 0.7623 & 0.7616 & 0.7116 & 0.7679 \\
\hline III-III/2 & 0.9172 & 0.9159 & 0.8676 & 0.9245 \\
\hline III-III/6 & 0.6888 & 0.6906 & 0.6718 & 0.6931 \\
\hline III-III/10 & 0.7225 & 0.7225 & 0.6713 & 0.7284 \\
\hline IA-IA/3 & 0.8554 & 0.8530 & 0.8018 & 0.8791 \\
\hline IA-IA/7 & 0.8495 & 0.8492 & 0.8560 & 0.8265 \\
\hline IA-IA/11 & 0.8294 & 0.8267 & 0.7830 & 0.8412 \\
\hline IIA-IIA/2 & 0.8905 & 0.8860 & 0.8287 & 0.8916 \\
\hline IIA-IIA/6 & 0.8580 & 0.8652 & 0.8806 & 0.8669 \\
\hline IIA-IIA/10 & 0.8053 & 0.8051 & 0.7619 & 0.8114 \\
\hline IIIA-IIIA/1 & 0.9043 & 0.9029 & 0.8435 & 0.9117 \\
\hline IIIA-IIIA/5 & 0.7531 & 0.7553 & 0.7689 & 0.7518 \\
\hline IIIA-IIIA/9 & 0.7438 & 0.7439 & 0.7035 & 0.7493 \\
\hline The average value & 0.8069 & 0.8063 & 0.7737 & 0.8113 \\
\hline
\end{tabular}

\subsection{Discussions}

Based on the results of the above examples, the following discussions are given:

1) The results of fuzzy displacements obtained by the proposed algorithm are close to that by the a-optimization method, which seems to be the "exact method" in the fuzzy analysis of structures. This demonstrates that the complete quadratic polynomial in which all fuzzy variables are standardized variables using the formulae (7), (8) and (9) is a reasonable regression model to determine fuzzy displacements of structures. In example 1, the results of the proposed algorithm are much more accurate than those of the algorithm of [28]. In example 2, the results of fuzzy displacements according to the proposed algorithm are slightly more accurate than ones according to the method of [5].

2) The formulae (14) and (15), which are based on the operation of the intersection on two fuzzy numbers, and the formulae (17), (18) in the proposed algorithm, have gained high accuracy for the results of fuzzy internal forces. In example 2, the percentage of errors in the lower and upper 
bounds for fuzzy axial forces of the proposed method regarding the corresponding of the extension principle is within a range of $0.0465 \%$ to $0.7658 \%$. This indicates that the accuracy of the proposed algorithm is quite higher than that of the method [5]. In example 3, by using the formulae (17) and (18), the proposed algorithm and the a-optimization method yield the same solutions to each other for 9 of 15 bars total $60 \%$. For the remaining bars, the average value of the relative difference between the two methods is within a range of $0 \%$ to $1.97 \%$. In example 4 , applying the similarity measure between two fuzzy numbers demonstrates that the proposed algorithm is the most reasonable approach in three approaches: the complete quadratic polynomial regression model, the non-complete quadratic polynomial regression model, the proposed algorithm. The average values of the similarity measures between the left-hand sides and the right-hand sides of the equations of equilibrium for forces and moments obtained by the proposed algorithm are very close to that by the a-optimization method. This also illustrates the adequate effectiveness of the proposed algorithm.

3) The number of computations obtained by the proposed algorithm is less than that by the vertex method [12]. Indeed, in example 2, the proposed algorithm requires 9 deterministic finite element problems, while 17 deterministic finite element problems need to analyze by the vertex method. In example 3, to determine fuzzy displacements at all nodes and fuzzy axial forces of all bars in the system, 62 deterministic finite element problems need to be analyzed by the proposed algorithm compared to 129 deterministic finite element problems that are required by the vertex method. These expressly indicate that besides achieving high accuracy, the proposed algorithm is also a solution to reduce the number of computations.

\section{Conclusions}

A new fuzzy finite element algorithm has been presented to calculate fuzzy responses of structures. The novel formulae for determining the standardized fuzzy variables of the general triangular fuzzy numbers are proposed and utilized in the quadratic polynomial regression models. Due to the suitable combination between the least-square error criterion and the operation of the intersection on two fuzzy numbers, both fuzzy displacements and fuzzy internal forces using the proposed algorithm are very close to the exact solutions of problems. The virtues of the proposed algorithm comprising accuracy and computational efficiency have been thoroughly verified through several examples. Based on the aforementioned specialities, the present study should be considered as one of the efficient methods in terms of application.

\section{References}

[1] DUBOIS, D.: Fuzzy sets and systems: theory and applications. Vol. 144, Academic press, 1980.

[2] ZHANG, H.: Nondeterministic linear static finite element analysis: an interval approach. PhD Thesis, Georgia Institute of Technology, 2005.

[3] MUHANNA, R. L. - ZHANG, H. - MULLEN, R. L.: Interval finite elements as a basis for generalized models of uncertainty in engineering mechanics. Reliable computing, Vol. 13, No. 2, 2007, pp. 173-194.

[4] RAO, M. R. - MULLEN, R. L. - MUHANNA, R. L.: A new interval finite element formulation with the same accuracy in primary and derived variables. International Journal of Reliability and Safety, Vol. 5, No. 3-4, 2011, pp. 336-357.

[5] DEGRAUWE, D. - LOMBAERT, G. - DE ROECK, G.: Improving interval analysis in finite element calculations by means of affine arithmetic. Computers \& Structures, Vol. 88, No. 3, 2010, pp. 247254.

[6] ADHIKARI, S. - KHODAPARAST, H. H.: A spectral approach for fuzzy uncertainty propagation in finite element analysis. Fuzzy Sets and Systems, Vol. 243, 2014, pp. 1-24.

[7] BEHERA, D. D. - CHAKRAVERTY, S. - HUANG, H. Z.: Non-probabilistic uncertain static responses of imprecisely defined structures with fuzzy parameters. Journal of Intelligent \& Fuzzy Systems, Vol. 30, 2016, pp. 3177-3189.

[8] SU, J. - ZHU, Y. - WANG, J.: An improved interval finite element method based on the elementby-element technique for large truss system and plane problems. Advances in Mechanical Engineering, Vol. 10, No. 4, 2018, pp. 1-10.

[9] MÖLLER, B. - BEER, M.: Fuzzy randomness: uncertainty in civil engineering and computational mechanics. Springer Science \& Business Media, 2004.

[10] DEGRAUWE, D.: Uncertainty Propagation in Structural Analysis by Fuzzy Numbers (Onzekerheidsvoortplanting in structuuranalyse met vaaggetallen), 2007. 
[11] FARKAS, L. - MOENS, D. - VANDEPITTE, D.: Fuzzy finite element analysis based on reanalysis technique. Structural Safety, Vol. 32, No. 6, 2010, pp. 442-448.

[12] DONG, W. - SHAH, H. C.: Vertex method for computing functions of fuzzy variables. Fuzzy Sets and Systems, Vol. 24, No. 1, 1987, pp. 65-78.

[13] HANSS, M.: Applied fuzzy arithmetic, Springer, 2005.

[14] DONDERS, S. - VANDEPITTE, D. - VAN DE PEER, J.: Assessment of uncertainty on structural dynamic responses with the short transformation method. Journal of Sound and Vibration, Vol. 288, No. 3, 2005, pp. 523-549.

[15] GIANNINI, O. - HANSS, M.: The component mode transformation method: a fast implementation of fuzzy arithmetic for uncertainty management in structural dynamics. Journal of Sound and Vibration, Vol. 311, No. 3-5, 2008, pp. 1340-1357.

[16] AKPAN, U. O. - KOKO, T. S. - ORISAMOLU, I. R.: Practical fuzzy finite element analysis of structures. Finite Elements in Analysis and Design, Vol. 38, No. 2, 2001, pp. 93-111.

[17] DE MUNCK, M. - MOENS, D. - DESMET, W.: A response surface based optimisation algorithm for the calculation of fuzzy envelope FRFs of models with uncertain properties. Computers \& Structures, Vol. 86, No. 10, 2008, pp. 1080-1092.

[18] BALU, A. S. - RAO, B. N.: High dimensional model representation based formulations for fuzzy finite element analysis of structures. Finite Elements in Analysis and Design, Vol. 50, 2012, pp. 217-230.

[19] TUAN, N. H. - HUYNH, L. X. - ANH, P. H.: A fuzzy finite element algorithm based on response surface method for free vibration analysis of structure. Vietnam Journal of Mechanics, Vol. 37, No. 1, 2015, pp. 17-27.

[20] PHAM, H. A. - TRUONG, V. H. - VU, T. C.: Fuzzy finite element analysis for free vibration response of functionally graded semi-rigid frame structures. Applied Mathematical Modelling, V. 88, 2020, pp. 852-869.

[21] DE GERSEM, H. - MOENS, D. - DESMET, W.: A fuzzy finite element procedure for the calculation of uncertain frequency response functions of damped structures: Part 2-Numerical case studies. Journal of Sound and Vibration, Vol. 288, No. 3, 2005, pp. 463-486.

[22] MOENS, D. - VANDEPITTE, D.: A fuzzy finite element procedure for the calculation of uncertain frequency-response functions of damped structures: Part 1-Procedure. Journal of sound and vibration, Vol. 288, N. 3, 2005, pp. 431-462.

[23] DE GERSEM, H. - MOENS, D. - DESMET, W.: Interval and fuzzy finite element analysis of mechanical structures with uncertain parameters. Proceedings of the International Conference on Noise and Vibration Engineering ISMA, 2004.

[24] MAJOR, I. - MAJOR, M.: Application of the Perturbation Method for Determination of Eigenvalues and Eigenvectors for the Assumed Static Strain. Civil and Environmental Engineering, Vol. 10, Iss. 2, 2014, pp. 111-120.

[25] STEFANOU, G.: The stochastic finite element method: past, present and future. Computer methods in applied mechanics and engineering, Vol. 198, No. 9-12, 2009, pp. 1031-1051.

[26] ZHENYU, L. - QIU, C.: A new approach to fuzzy finite element analysis. Computer methods in applied mechanics and engineering, Vol. 191, No. 45, 2002, pp. 5113-5118.

[27] HUANG, H. Z. - LI, H. B.: Perturbation finite element method of structural analysis under fuzzy environments. Engineering Applications of Artificial Intelligence, Vol. 18, No. 1, 2005, pp. 83-91.

[28] ANH, P. H.: Fuzzy analysis of laterally-loaded pile in layered soil. Vietnam Journal of Mechanics, Vol. 36, No. 3, 2014, pp. 173-183.

[29] MASON, R. L. - GUNST, R. F. - HESS, J. L.: Statistical design and analysis of experiments: with applications to engineering and science, Vol. 474, John Wiley \& Sons, 2003.

[30] TRAN, T. V. - VU, Q. A. - LE, X. H.: Fuzzy analysis for stability of steel frame with fixity factor modelled as triangular fuzzy number. Advances in computational design, Vol. 2, No. 1, 2017, pp. 29-42.

[31] DUBOIS, D.: Possibility theory and statistical reasoning. Computational statistics \& data analysis, Vol. 51, No. 1, 2006, pp. 47-69.

[32] DUBOIS, D. - FOULLOY, L. - MAURIS, G.: Probability-possibility transformations, triangular fuzzy sets, and probabilistic inequalities. Reliable computing, Vol. 10, No. 4, 2004, pp. 273-297.

[33] DUBOIS, D. - PRADE, H.: Possibility theory and its applications: Where do we stand? Springer handbook of computational intelligence, Springer, 2015, pp. 31-60.

[34] QUEIPO, N. V. - HAFTKA, R. T. - SHYY, W.: Surrogate-based analysis and optimization. Progress in aerospace sciences, Vol. 41, No. 1, 2005, pp. 1-28.

[35] MICHALEWICZ, Z.: Genetic algorithms+ data structures= evolution programs. Springer Science \& Business Media, 2013. 
[36] TEODORU, I. B. - MUŞAT, V.: The modified Vlasov foundation model: an attractive approach for beams resting on elastic supports. EJGE, Vol. 15, 2010, pp.1-13.

[37] CHOU, C. C.: A generalized similarity measure for fuzzy numbers. Journal of Intelligent \& Fuzzy Systems, Vol. 30, No. 2, 2016, pp. 1147-1155. 